\title{
COVID-19 in Continental America
}

\author{
Leila Moradi (iD ${ }^{1, *}$ \\ ${ }^{1}$ Department of Epidemiology, School of Public Health, Hamadan University of Medical Sciences, Hamadan, Iran \\ "Corresponding author: Department of Epidemiology, School of Public Health, Hamadan University of Medical Sciences, Hamadan, Iran. Email: leilamoradio73@gmail.com
}

Received 2021 July 05; Accepted 2021 August 10.

\begin{abstract}
Background: In late December 2019, a coronavirus outbreak first occurred in Wuhan, China, and then spread worldwide, which became a major global emergency. This severe respiratory illness called coronavirus disease 2019 (COVID-19) is transmitted through respiratory droplets and contaminated surfaces.

Objectives: This study aimed to investigate the epidemiology of COVID-19 in continental America.

Methods: This study was an ecological study describing the epidemiological features of COVID-19 in the Americas. The data of identified definitive cases and deaths from this disease and other information were extracted from the reports of the World Health Organization and transferred to SPSS software (version 24). Furthermore, the case fatality rate was separately calculated for each country. Results: The highest number of COVID-19 reported cases and the highest COVID-19 mortality rate were in the United States, with $72,186,963$ and 1,896,955 cases, respectively. Moreover, the highest case fatality rate was reported as $9.38 \%$ in Peru.

Conclusions: The prevention of COVID-19 transmission in countries is possible with general vaccination and observation of social distancing. These measures reduce the transmission of COVID-19 and are effective ways to control this global health problem.
\end{abstract}

Keywords: COVID-19, Coronavirus, America

\section{Background}

The outbreak of an emerging respiratory syndrome occurred in Wuhan, China, in late December 2019 (1). The cause of the outbreak was a coronavirus, and the World Health Organization (WHO) officially named the respiratory illness coronavirus disease 2019 (COVID-19). The symptoms of this disease are severe fever and cough, pneumonia, respiratory infection, and lung infection (2). Elderly individuals with chronic diseases are more prone to severe cases of the disease (3).

Several similar outbreaks have been reported from Chinese cities (4). After initial research, bats were identified as the primary source of the disease (5). The worldwide spread of the disease led to the official declaration of COVID-19 as a pandemic by the WHO in March 2020 (6). In some countries, the spread of COVID-19 has been reduced and controlled; however, the general situation in the world is changing and getting worse, and the measures taken in most countries have not been effective (7). This pandemic is a great threat to all countries, especially the middle- and low-income countries (8).

This respiratory disease is transmitted mainly through droplets and hand contact with contaminated surfaces (9). The COVID-19 has been rapidly spreading worldwide and has caused a major health problem in populous countries that do not have adequate health care systems (10). The transmission of the disease from healthy carriers and limited access to testing to identify patients are important factors in the rapid spread of the disease (11). After the spread of COVID-19 in most countries, health interventions were carried out, including observing social distancing and enforcing traffic restrictions and quarantine laws (12). According to epidemiological estimates and statistical models, the death toll from COVID-19 in populous countries is likely to reach one million (13).

\section{Objectives}

This study aimed to investigate the epidemiology of COVID-19 in the Americas. 


\section{Methods}

This study was an ecological study that examined the status of COVID-19 in continental America. The data on the total number of definitive COVID-19 cases and the total number of definitive COVID-19 deaths by country and the population of the Americas were extracted from the WHO reports $(14,15)$. This information was collected from the beginning up to June 30, 2021. The data were transferred to SPSS software (version 24), and the case fatality rate was separately calculated for each country using the following formula (16):

Case fatality rate $(\%)=($ No of individuals dying during a specified period after disease onset or diagnosis / No individuals with the specified disease $) \times 100$

\section{Results}

The total number of countries in the Americas, according to the WHO, is reported as 44 countries, the most populous of which is the United States of America with $322,180,000$ individuals and the least populous of which are the Turks and Caicos Islands with 31,458 individuals. The highest and lowest numbers of confirmed cases of COVID-19 were related to the United States of America and Grenada, with 72,186,963 and 162 cases, respectively. In addition, the highest and lowest numbers of definitive mortalities due to COVID-19 were reported as 1,896,955 and 1 cases in the United States of America and Grenada, respectively. The highest and lowest case fatality rates were $9.38 \%$ and $0.33 \%$ in Peru and the Cayman Islands, respectively (Table 1).

\section{Discussion}

According to the results of this study, the most definite cases of COVID-19 identified in the Americas belonged to the three countries of the United States of America, Brazil, and Argentina, respectively. A study performed by Scannell Bryan et al., investigating the mortalities from COVID-19 in the United States, demonstrated that blacks were more likely to die than whites and the average age of death in Spain was lower than that of other races, with more than half mortalities (17). A study conducted by Alcendor, investigating the mortalities from COVID-19 in demographic minorities, showed that the mortality rate was higher in
African Americans and Hispanics due to poverty, low economic status, and limited access to social and health services. They also had an underlying disease that increased their risk of death from COVID-19 (18).

The results of a study carried out by Asare et al. in the United States showed that more than $40 \%$ of deaths in patients with COVID-19 were in obese individuals, and there was no gender difference (19). In a study performed by Werneck et al., examining COVID-19 in Brazil, the lack of sufficient information on the transmission of the disease, social inequalities in access to health services, and overcrowding were identified as effective factors in disease transmission (20). The results of a study conducted by Fernández-Rojas et al., examining the causes of COVID19 in Mexico, showed that the disease was more disseminated in sparsely populated cities, which may have been due to less access to diagnostic and health facilities and economic and social levels. Moreover, low economic and social levels and high prevalence of chronic diseases may increase the risk of COVID-19 in the residents of sparsely populated cities. In examining the relationship between occupation and risk of COVID-19, informal occupations and businesses were also high-risk, and the employees of various departments were low-risk, where high-risk occupations may have transmitted more due to high contact with different individuals (21).

An important recommendation after obtaining the results of this study is general vaccination with priority for the elderly chronic patients who are high-risk groups in case of COVID-19.

\section{Footnotes}

Conflict of Interests: It was not declared by the authors. Funding/Support: The authors received no funding or support. 


\begin{tabular}{|c|c|c|c|c|}
\hline Country & Population & Total COVID-19 Cases & Total COVID-19 Mortality Cases & Case Fatality Rate \\
\hline United States of America & 322180000 & 72186963 & 1896955 & 2.63 \\
\hline Brazil & 207653000 & 18488402 & 514092 & 2.78 \\
\hline Argentina & 43847000 & 4423306 & 93142 & 2.11 \\
\hline Colombia & 48653000 & 4187194 & 105326 & 2.52 \\
\hline Mexico & 127540000 & 2507453 & 232608 & 9.28 \\
\hline Peru & 31774000 & 2049567 & 192163 & 9.38 \\
\hline Chile & 17910000 & 1553774 & 32849 & 2.11 \\
\hline Canada & 36290000 & 1414134 & 26238 & 1.86 \\
\hline Ecuador & 19385000 & 455743 & 21523 & 4.72 \\
\hline Bolivia & 10888000 & 435568 & 16631 & 3.82 \\
\hline Paraguay & 6725000 & 419764 & 12641 & 3.01 \\
\hline Panama & 4034000 & 401322 & 6529 & 1.63 \\
\hline Uruguay & 3444000 & 366915 & 5524 & 1.51 \\
\hline Costa Rica & 48653000 & 364304 & 4648 & 1.28 \\
\hline Dominican & 10649000 & 324364 & 3815 & 1.18 \\
\hline Guatemala & 16582000 & 292674 & 9147 & 3.12 \\
\hline Venezuela & 31568000 & 270654 & 3084 & 1.14 \\
\hline Honduras & 9113000 & 260331 & 6922 & 2.66 \\
\hline Cuba & 11476000 & 188023 & 1270 & 0.68 \\
\hline Puerto Rico & 3474182 & 140021 & 1270 & 0.91 \\
\hline El Salvador & 6345000 & 78766 & 2376 & 3.02 \\
\hline Jamaica & 2881000 & 50080 & 1065 & 2.13 \\
\hline Trinidad and Tobago & 1365000 & 32343 & 822 & 2.54 \\
\hline Suriname & 541638 & 21360 & 512 & 2.40 \\
\hline Guyana & 773000 & 19891 & 466 & 2.34 \\
\hline Haiti & 10911819 & 18562 & 425 & 2.29 \\
\hline Belize & 367000 & 13189 & 329 & 2.49 \\
\hline Bahamas & 391000 & 12586 & 246 & 1.95 \\
\hline Curacao & 158986 & 12332 & 126 & 1.02 \\
\hline Martinique & 402119 & 12286 & 98 & 0.80 \\
\hline Aruba & 108374 & 11132 & 107 & 0.96 \\
\hline Nicaragua & 6150000 & 6604 & 191 & 2.89 \\
\hline Snit Maarten & 37224 & 2613 & 33 & 1.26 \\
\hline Turks and Caicos Islands & 31458 & 2424 & 18 & 0.74 \\
\hline Saint Martin & 37224 & 2613 & 33 & 1.26 \\
\hline Cayman Islands & 60413 & 614 & 2 & 0.33 \\
\hline Barbados & 285000 & 4079 & 47 & 1.15 \\
\hline Bermuda & 61695 & 2514 & 33 & 1.31 \\
\hline Saint Lucia & 178000 & 5284 & 84 & 1.59 \\
\hline Antigua and Barbuda & 90755 & 1263 & 42 & 3.33 \\
\hline Saint Vincent and the Grenadin & 110000 & 2219 & 12 & 0.54 \\
\hline British Virgin Islands & 34232 & 298 & 1 & 0.34 \\
\hline Grenada & 107000 & 162 & 1 & 0.62 \\
\hline Saint Kitts and Nevis & 55000 & 439 & 3 & 0.68 \\
\hline
\end{tabular}

Abbreviation: COVID-19, coronavirus disease 2019.

\section{References}

1. Huang X, Wei F, Hu L, Wen L, Chen K. Epidemiology and clinical characteristics of COVID-19. Arch Iran Med. 2020;23(4):268-71. doi: 10.34172/aim.2020.09. [PubMed: 32271601].

2. Adhikari SP, Meng S, Wu YJ, Mao YP, Ye RX, Wang QZ, et al. Epidemiology, causes, clinical manifestation and diagnosis, prevention and control of coronavirus disease (COVID-19) during the early out- break period: a scoping review. Infect Dis Poverty. 2020;9(1):29. doi: 10.1186/s40249-020-00646-x. [PubMed: 32183901]. [PubMed Central: PMC7079521].

3. Pettit NN, MacKenzie EL, Ridgway JP, Pursell K, Ash D, Patel B, et al. Obesity is associated with increased risk for mortality among hospitalized patients with COVID-19. Obesity (Silver Spring). 2020;28(10):180610. doi: 10.1002/oby.22941. [PubMed: 32589784]. [PubMed Central: PMC7362135]. 
4. Lipsitch M, Swerdlow DL, Finelli L. Defining the epidemiology of Covid-19 - studies needed. N Engl J Med. 2020;382(13):1194-6. doi: 10.1056/NEJMp2002125. [PubMed: 32074416].

5. Bulut C, Kato Y. Epidemiology of COVID-19. Turk J Med Sci. 2020;50(SI1):563-70. doi: 10.3906/sag-2004-172. [PubMed: 32299206]. [PubMed Central: PMC7195982].

6. Ciotti M, Ciccozzi M, Terrinoni A, Jiang WC, Wang CB, Bernardini S. The COVID-19 pandemic. Crit Rev Clin Lab Sci. 2020;57(6):365-88. doi: 10.1080/10408363.2020.1783198. [PubMed: 32645276].

7. Koks S, Williams RW, Quinn J, Farzaneh F, Conran N, Tsai SJ, et al. COVID-19: Time for precision epidemiology. Exp Biol Med (Maywood). 2020;245(8):677-9. doi: 10.1177/1535370220919349. [PubMed: 32301338]. [PubMed Central: PMC7221487].

8. Lone SA, Ahmad A. COVID-19 pandemic - an African perspective. Emerg Microbes Infect. 2020;9(1):1300-8. doi: 10.1080/22221751.2020.1775132. [PubMed: 32458760]. [PubMed Central: PMC7473237].

9. Zhai P, Ding Y, Wu X, Long J, Zhong Y, Li Y. The epidemiology, diagnosis and treatment of COVID-19. Int J Antimicrob Agents. 2020;55(5):105955. doi: 10.1016/j.ijantimicag.2020.105955. [PubMed:32234468]. [PubMed Central: PMC7138178].

10. Fiorillo A, Gorwood P. The consequences of the COVID-19 pandemic on mental health and implications for clinical practice. Eur Psychiatry. 2020;63(1). e32. doi: 10.1192/j.eurpsy.2020.35. [PubMed: 32234102]. [PubMed Central: PMC7156565].

11. Dhar Chowdhury S, Oommen AM. Epidemiology of COVID-19. J Dig Endosc. 2020;11(1):3-7. doi: 10.1055/s-0040-1712187.

12. Olwenyi OA, Dyavar SR, Acharya A, Podany AT, Fletcher CV, Ng CL, et al. Immuno-epidemiology and pathophysiology of coronavirus disease 2019 (COVID-19). J Mol Med (Berl). 2020;98(10):1369-83. doi: 10.1007/s00109-020-01961-4. [PubMed: 32808094]. [PubMed Central: PMC7431311].

13. Goldstein JR, Lee RD. Demographic perspectives on the mortal- ity of COVID-19 and other epidemics. Proc Natl Acad Sci U S A. 2020;117(36):22035-41. doi: 10.1073/pnas.2006392117. [PubMed: 32820077]. [PubMed Central: PMC7486771].

14. WHO. WHO coronavirus disease (COVID-19) dashboard 2021. 2021. Available from: https://covid19.who.int/table.

15. WHO. Countries and Centers. 2021, [updated 2021]. Available from: https://www.paho.org/en/countries-and-centers.

16. Gordis L. Epidemiology. 4th ed. Philadelphia: Saunders; 2008.

17. Scannell Bryan M, Sun J, Jagai J, Horton DE, Montgomery A, Sargis R, et al. Coronavirus disease 2019 (COVID-19) mortality and neighborhood characteristics in Chicago. Ann Epidemiol. 2021;56:47-54 e5. doi: 10.1016/j.annepidem.2020.10.011. [PubMed: 33181262]. [PubMed Central: PMC7678719].

18. Alcendor DJ. Racial disparities-associated COVID-19 mortality among minority populations in the US. J Clin Med. 2020;9(8). doi: 10.3390/jcm9082442. [PubMed: 32751633]. [PubMed Central: PMC7466083].

19. Asare S, Sandio A, Opara IN, Riddle-Jones L, Palla M, Renny N, et al. Higher obesity trends among African Americans are associated with increased mortality in infected COVID-19 patients within the city of Detroit. SN Compr Clin Med.2020:1-3. doi:10.1007/s42399-020-00385-y. [PubMed: 32838154]. [PubMed Central: PMC7324487].

20. Werneck GL, Carvalho MS. The COVID-19 pandemic in Brazil: a chronicle of a health crisis foretold. Cadernos de Saúde Pública. 2020;36(5). doi: 10.1590/0102-311x00068820. [PubMed: 32402007].

21. Fernandez-Rojas MA, Luna-Ruiz Esparza MA, Campos-Romero A, Calva-Espinosa DY, Moreno-Camacho JL, Langle-Martinez AP, et al. Epidemiology of COVID-19 in Mexico: Symptomatic profiles and presymptomatic people. Int J Infect Dis. 2021;104:572-9. doi: 10.1016/j.ijid.2020.12.086. [PubMed: 33434668]. [PubMed Central: PMC7831729]. 